\title{
Influence of Binder type on Greenhouse Gases and PAHs from the Pyrolysis of Biomass Briquettes
}

\author{
L. Florentino-Madiedo, E. Díaz-Faes, R. García, C. Barriocanal ${ }^{\star}$ \\ Instituto Nacional del Carbón, INCAR-CSIC, Apartado 73, 33080 Oviedo. Spain \\ ${ }^{*}$ Corresponding autor: carmenbr@incar.csic.es
}

\section{Abstract}

Five blends prepared with torrified sawdust, coal plus either coal tar, coal tar sludge, paraffin or molasses designed to serve as binder in the preparation of briquettes were pyrolysed in a rotary oven. The coal and the torrified sawdust used in the preparation of the blends were also studied. The condensable gases were analyzed by gas chromatography (GC) and infrared spectroscopy (FTIR). The permanent gases were also analyzed by gas chromatography. The concentration of nineteen polyaromatic hydrocarbons in the condensable products was analyzed with special focus on those considered as priority and carcinogenic pollutants. The results obtained from FTIR were confirmed by those obtained by GC. It was found that the inclusion of biomass produces a decrease in the amount of (polyaromatic hydrocarbons) PAHs in the condensable pyrolysis products and an increase in the concentration of $\mathrm{CO}_{2}$ in the gases, although these gases are carbon neutral.

Keywords: Coal, biomass, briquettes, PAH, GHG 


\section{Introduction}

Pyrolysis is a widely used technology that is applied in a large number of processes. Biomass pyrolysis produces bio-oil, charcoal and gas that can be converted into syngas for renewable energy production [1], whereas charcoal can be used as a reductant in the blast furnace [2] and biofuels can be produced from the liquid pyrolysis products. Social concern about greenhouse gases has given an impulse to the drive to replace fossil fuel with biomass with the aim of reducing the impact of these gases on the environment.

Of these GHG (Green House Gases), two of them (i.e. carbon dioxide and methane), are of special concern. Methane is less abundant than $\mathrm{CO}_{2}$ in the atmosphere, but its global warming potential is about 28-36 times more deleterious than $\mathrm{CO}_{2}$ [3]. European coke plants emit to the atmosphere around $0.794 \mathrm{t} \mathrm{CO}_{2} / \mathrm{t}$ coke [4]. Volatile organic compounds (VOCs) are considered to be one of the major contributors to air pollution. Some types of alkenes like propylene, produced in the pyrolysis process, has the potential to create a large layer of photochemical ozone [5]. Coal coking produces coke and vapors that are cooled down to obtain coal tar and permanent gases that are used to heat the ovens. The use of biomass in the blends will modify the composition of the tar, permanent gases and emission of PAHs during the process. Tar distillation and coke production, are considered to be two of the main sources of polycyclic aromatic hydrocarbons (PAHs), which are a family of VOCs [6]. These pollutants are the cause of great concern due to their carcinogenicity and mutagenicity. Long-term exposure to $\mathrm{PAH}$-rich emissions is associated with a greater risk of lung cancer in workers exposed to such contaminants. Moreover soil contamination poses another problem as crops may absorb PAHs from contaminated soil, allowing the transfer of PAHs to humans via the food chain [6-8].

Environmental concerns have increased the need to implement new technologies to obtain sustainable energy and derived products from biomass. 
Biomass-based reducing agents offer an excellent opportunity for decreasing $\mathrm{CO}_{2}$ emissions in the steelmaking industry. However, charcoal is not suitable for replacing lump coke directly in a blast furnace due to its insufficient strength compared to coke [9]. This is the reason why biocoke produced from blends of coal and biomass are the subject of intensive study in an attempt to find a suitable alternative to coke [2].

One of the problems associated with the use of biomass is its low density, a possible solution for which might be the preparation of briquettes using biomass and a binder [10]. Coal tar has also been considered as binder for such briquettes but its disadvantage is that produces a substantial increase in the emission of PAHs [11].

In order to produce briquettes for use in the pyrolysis/carbonization process, four different binders were selected in order to determine their effect on the concentration of polyaromatic hydrocarbons present in the condensable products and on the production of greenhouse gases during co-pyrolysis with sawdust and coal.

\section{Materials and methods}

A bituminous coal (Coal), a pine sawdust torrified at $300^{\circ} \mathrm{C}$ for $1 \mathrm{~h}$ (SP4T) and four binders (i.e. paraffin (P), molasses (M), coal-tar $(\mathrm{T})$ and coal-tar sludge (CTS)), were selected in order to prepare five different blends for use in the preparation of the briquettes. The coal and the sawdust were also studied individually in order to compare the effect of the binders. Pine sawdust was obtained as a waste from timber industry, two of the binders are also wastes (i.e., CTS was obtained from the tar decanter of an integrated steel plant while the molasses were taken from sugar cane industry). The coal-tar and the paraffin are both commercial products used as binders for the preparation of briquettes.

The composition of the five blends used is shown in Table 1. BT, BCTS, BP and BM have the same proportions of coal, SP4T and binder, 70 wt. $\%, 15$ wt.\% and 15 wt.\% respectively. In the case of the molasses, another blend (B10M) containing $70 \mathrm{wt} . \%$ coal, 
20 wt.\% SP4T and 10 wt.\% molasses was studied since in our experience the amount of binder needed is lower if molasses is used.

Proximate analyses were performed following the ISO 562 and ISO 1171 standard procedures for volatile matter and ash content, respectively. The elemental analysis was determined with the aid of a LECO CHN-2000 for C, H and N (ASTM D-5773), a LECO S-144 DR for sulfur (ASTM D-5016) and a LECO VTF-900 for the direct determination of oxygen.

\subsection{Pyrolysis and characterization of tar and gas}

The pyrolysis experiments were carried out with the coal, the torrified sawdust (SP4T) and the five blends (BT, BCTS, BP, BM and B10M). The coal and paraffin were ground to sizes smaller than $1 \mathrm{~mm}$ and $0.425 \mathrm{~mm}$ respectively. The other raw materials were used as received: 19.3 wt\% of the torrified sawdust had a particle size above $1 \mathrm{~mm}$, whereas the rest ( $80.7 \mathrm{wt} \%)$ was of a smaller particle size. Around $40 \mathrm{~g}$ of sample was heated up to $1000{ }^{\circ} \mathrm{C}$ at a rate of $3{ }^{\circ} \mathrm{C} / \mathrm{min}$ under a $\mathrm{N}_{2}$ flow of $100 \mathrm{~mL} / \mathrm{min}$, applying a soaking time of $1 \mathrm{~h}$. The condensation products were collected from an oil trap connected to the end of the reactor and a column filled with amberlite resin. A diagram showing the configuration of the oven has been published previously [12]. The error associated with the determination of the coke yield was lower than $1 \%$ while that of the liquid and gas yields was lower than $3 \%$.

Gases were collected in Tedlar® gas bags connected to the system downstream of the gas condensation traps used to collect the pyrolysis gases.

The tars were subjected to elemental analysis, Fourier transform infrared spectroscopy (FTIR) and Gas chromatography (GC) using flame ionization (FID).

The elemental analysis of the pyrolysis tars was determined as explained in section 2.1. 
Fourier transform infrared spectroscopy (FTIR) spectra were recorded on a Nicolet Magna-IR560 spectrometer equipped with a DTGS detector. The sample was deposited as a thin film between the $\mathrm{NaCl}$ windows and subjected to 128 scans at a resolution of 4 $\mathrm{cm}^{-1}$ in the $4000-600 \mathrm{~cm}^{-1}$ range in order to obtain the spectra. Selected indices obtained from the FTIR data using the integrated area $(A)$ or the maximum intensity $(H)$ of different absorption bands were employed for the semiquantitative analyses. The values of the indices were calculated from the average of four spectra obtained from two different droplets.

For the chromatographic PAH analysis, representative aliquot portions were taken from each sample and dissolved in toluene using a sonicated water bath. The solutions obtained were filtered by means of a Teflon filter of $45 \mu \mathrm{m}$ pore size to remove any undissolved material. D10-acenaphthene, 2-ethylanthracene and D12-perylene were added to the filtered solutions as internal standards. From each sample three different solutions were prepared and injected into an Agilent Model 6890 gas chromatograph equipped with a flame ionization detector and a VF-5ms fused-silica capillary column (i.d. $0.32 \mathrm{~mm}$, length, $30 \mathrm{~m}$; film thickness, $0.25 \mu \mathrm{m}$ ) coated with $5 \%$ phenyl methylpolysiloxane as stationary phase. Helium was employed as the carrier gas at a flow rate of $1.5 \mathrm{~mL} / \mathrm{min}$. The temperatures of the detector and the injector were $320{ }^{\circ} \mathrm{C}$ and $300^{\circ} \mathrm{C}$, respectively. The results reported are the average of three determinations. The error in the determination was in all cases lower than $1 \%$

The gases derived from the pyrolysis were analyzed in an Agilent 490 micro GC equipped with a TCD detector and three channels; CP-Molsieve 5A column, PPQ (Pora Plot Q) and CP-Sil 5 CB. Nitrogen was used as the carrier gas in the PPQ and CP-Sil 5 CB channels, while Argon was employed for the CP-Molsieve 5A channel. The quantitative analysis was carried out using blends of gases of known composition. The results reported are the average of three determinations. The error in the determination was in all cases lower than $1 \%$. 


\section{Results and Discussion}

\subsection{Main characteristics of the raw materials}

The results of the proximate and elemental analyses of the raw materials are shown in Table 2. The coal has a higher ash and lower volatile matter content than the rest of the raw materials. Therefore the coke yield from the coal must be the highest. The biomasses have a low carbon content (SP4T, $55.7 \mathrm{wt} \% \%$ and molasses, $26.5 \mathrm{wt} . \%$ ) and a high oxygen content (SP4T, 39.0 wt.\% and molasses, 55.9 wt.\%). In general biomass has a C content below 50 wt. $\%$ and $\mathrm{O}$ content above 40 wt.\% [9]. Whereas, paraffin has very low oxygen content. Materials with a high oxygen content when blended with coal tend to increase its reactivity resulting in less ordered materials [13,14].

\subsection{Mass balance}

Figure 1 shows the mass balance resulting from the pyrolysis of the coal, the torrified sawdust and blends. The coke yield is directly related to the volatile matter content of the blends (correlation coefficient $r=0.922$ ) which was calculated, taking into account the volatile matter of the blend components and the law of additivity (Table 2). The yields from coal (i.e. coke=71.9 wt\%, tar=13.2 wt\%, gas=15.0 wt\%) and from SP4T (coke=29.9 $w t \%, \operatorname{tar}=32.7 w t \%$, gas $=37.3 w t . \%)$ are similar to those obtained by other authors $[11,15]$, although slightly lower tar and higher gas yields were obtained in the present research work due to the configuration of the oven which favors the occurrence of secondary reactions [16]. In the case of the blends, their coke yields are similar and range from 56.0 to $62.4 \mathrm{wt} \%$ for $\mathrm{BP}$ and $\mathrm{BT}$ respectively. On the other hand, the highest gas yields correspond to SP4T and to the blends containing paraffin and molasses. The higher percentage of gas in blend $\mathrm{B} 10 \mathrm{M}$ compared to that in $\mathrm{BM}$ evidences that the increase in gas production is due to the torrified sawdust.

\subsection{Main characteristics of the pyrolysis tars}


The results of the elemental analysis of the tars obtained from the pyrolysis of the samples at $1000{ }^{\circ} \mathrm{C}$ are presented in Table 3 . What is most striking are the differences in oxygen content. Tars from the blends containing molasses (BM and B10M) have a high oxygen percentage (13.5 wt.\% and 11.4 wt.\% respectively). This result was expected because of the high O wt.\% content in the molasses (55.9 wt.\%). Nevertheless the tar from the blend that contains paraffin also has a high oxygen percentage (7.6 wt.\%); which is an unexpected result considering that paraffin has the lowest oxygen content of all the raw materials (0.3 wt.\%). Consequently some kind of synergism must be occurring in the reaction system involving the paraffin, coal and biomass that is causing oxygenated compounds to be retained in the condensable gases with the result that a tar with an oxygen content higher than that of the BT and BCTS is produced even though $\mathrm{T}$ and CTS have higher oxygen contents than $\mathrm{P}$ (Table 2, 3.0 and $6.6 \mathrm{wt} \%$ respectively vs. $0.3 \mathrm{wt} \%$ ). As will be seen later, the results of the FTIR analysis confirm the presence of a large number of oxygenated functionalities in the pyrolysis liquid obtained from BP. The S content of the pyrolysis tars is lower than that of the coal in all the blends but especially in the blend prepared with paraffin which is less than half that of the $S$ in the tar obtained from the coal. What is more, sulfur content is a very important parameter in the fuel industry. For marine diesel oil the maximum limit is 2 wt.\%. In the case of medium fuel oil for use in furnaces and boilers the maximum allowable sulphur content is 3 wt.\% [16].

The calorific value of the tars, calculated using the Dulong equation [17], is lower in the blends and sawdust than in the coal except in case of BP due to its high $\mathrm{C}$ and $\mathrm{H}$ content.

The FTIR spectra corresponding to the pyrolysis liquids obtained from the coal, torrified sawdust and the blends are displayed in Figure 2.

A number of common absorption bands are discernible and have been divided into the following groups: 
1. Range between $3100-2990 \mathrm{~cm}^{-1}$ assigned to the aromatic stretching of $\mathrm{C}-\mathrm{H}$.

2. Range between $2990-2765 \mathrm{~cm}^{-1}$ assigned to the aliphatic stretching of $\mathrm{C}-\mathrm{H}$.

3. Range between $1800-1538 \mathrm{~cm}^{-1}$ corresponding to the $\mathrm{C}=\mathrm{O}$ and $\mathrm{C}=\mathrm{C}$ stretching modes. The $1600 \mathrm{~cm}^{-1}$ band has been assigned to the $\mathrm{C}=\mathrm{C}$ stretching vibrations of the aromatic rings. Various stretching peaks that appear between 1800 and $1600 \mathrm{~cm}^{-1}$ have been assigned to $\mathrm{C}=\mathrm{O}$. these indicate the presence of esters, ketones, aldehyde and carboxylic groups [18,19].

4. Flexion in methylene and methyl groups at 1450 and $1375 \mathrm{~cm}^{-1}$ respectively.

5. The $900-700 \mathrm{~cm}^{-1}$ range corresponding to the out-of-plane aromatic $\mathrm{C}-\mathrm{H}$ vibration modes reveals differences in the substitution patterns of the aromatic structures.

Worth noting are the intense bands at 720 and $1450 \mathrm{~cm}^{-1}$ present in the tar from the blend containing paraffin that are due to the methylene group in long aliphatic chains. Also worthy of note is the intense shoulder in the range assigned to conjugated $\mathrm{C}=\mathrm{O}$. In the tars from BT and BCTS the bands in the range between 3100 and $2990 \mathrm{~cm}^{-1}$ are more intense than in the other tars reflecting the aromatic nature of these products. Their aromatic nature is confirmed by the intense bands at $750 \mathrm{~cm}^{-1}$ that indicate a smaller number of terminal benzenic rings [20].

A semiquantitative analysis of the spectra was carried out in order to establish the most important differences between the pyrolysis tars. Five indices were calculated, as shown in Table 4 [21]. lar conveys an idea of the degree of aromaticity of the tar; lo serves to quantify the amount of different $C=O$ functionalities $[19,21]$; Ic is the condensation index; $\mathrm{I}_{\mathrm{CH} 3 / \mathrm{CH} 2}$ indicates the length of the aliphatic chains $[11,22]$ and $\mathrm{H} 750$ indicates the bending vibration of $\mathrm{C}-\mathrm{H}$ in the aromatic structures where there are 4 neighbouring $\mathrm{H}$ atoms. The $\mathrm{H} 750$ index is directly related to the aromaticity index (lar) $(r=0.958)$ and to the condensation index (Ic) $(r=0.812)$ and all three are indicative of the amount of compounds with a large number of aromatic rings. The elemental composition of the pyrolysis tars $(\mathrm{H} / \mathrm{C}$ atomic ratio) is also inversely related to their lar index $(r=0.905$, 
SP4T was not considered for this correlation) and this relationship indicates a good concordance of the results obtained by different techniques. The pyrolysis oils that are the most aromatic and condensed are those taken from the blends prepared with $\mathrm{T}$ and CTS (lar $=0.243$, Ic $=2.163$ and $H 750=0.397$, being the average values obtained for the pyrolysis liquids from BT and BCTS) whereas that obtained from the blend with $\mathrm{P}$ has a very low aromatic character ( $\operatorname{lar}=0.041$, Ic $=0.884$ and $\mathrm{H} 750=0.237$ ), which agrees with the value of the $\mathrm{I}_{\mathrm{CH} 3 / \mathrm{ICH} 2}$ index that indicates the aliphatic character of this product with its long aliphatic chains. The oxygenated functionalities containing the $\mathrm{C}=\mathrm{O}$ bond were assessed by means of the $\mathrm{I}_{0}$ index (Table 5 ) the highest value of which corresponds to SP4T, as expected given of the high oxygen content of the torrified sawdust and of the tar derived from it. In the case of the blends the highest lo index value was calculated for the blend with paraffin (BP) which was unexpected considering the low oxygen content of the paraffin $(\mathrm{O}=0.3 \mathrm{wt} \% \mathrm{db})$. However, this is in agreement with the high oxygen content of the pyrolysis tar from blend BP (i.e. $7.6 \mathrm{wt} \% \mathrm{db}$, the $2^{\text {nd }}$ highest of the pyrolysis tars/oils obtained from the blends, Table 3). The combination of the long aliphatic chains and the high oxygen content of the torrified sawdust may cause the formation of large number of condensable compounds with a $\mathrm{C}=\mathrm{O}$ bond in their structure. During the pyrolysis of the paraffin the $\mathrm{C}-\mathrm{C}$ bonds are broken to produce alkanes and alkenes, whereas the breakage of $\mathrm{C}-\mathrm{H}$ bonds produces alkenes and $\mathrm{H}_{2}$. Moreover, these alkenes at high temperature and in the presence of $\mathrm{H}_{2}$ and $\mathrm{CO}$ derived from biomass pyrolysis may become oxidised and form $\mathrm{C}=\mathrm{O}$ groups [23]

The oxygen content of the pyrolysis tar is directly related to the $l_{0}$ index $(r=0.901$, the blends with molasses and the torrified sawdust have not been included). The oxygen content of the tars produced from the blends containing molasses is too high to fit into the correlation, probably because other oxygen functionalities apart from $\mathrm{C}=\mathrm{O}$ are present in high amounts, such as $-\mathrm{OH}$ (see the band in the range between 3600 and $3100 \mathrm{~cm}^{-1}$ in Figure 2). 
A detailed quantitative analysis of the polyaromatic hydrocarbons present in the pyrolysis tars was carried out in order to identify the compounds present and their dangerousness as function of the binder used in the blend. Figure 3 shows the gas chromatograms of the toluene soluble fraction of the pyrolysis tars. The numbers correspond to the peak identifications in the Figure caption. Table 6 contains the quantitative analysis data corresponding to nineteen PAHs including those considered by the USEPA (United States Environmental Protection Agency) as 16 priority-pollutants (PAH16, in Table 6 appear with an $\left.{ }^{*}\right)$. The bio-oil from SP4T produces a lower concentration of PAHs compared to the pyrolysis liquid from the coal ( $\Sigma \mathrm{PAH} 19=8.2 \mathrm{vs}$, $21.8 \mathrm{mg} / \mathrm{g}$ ). Nevertheless, this is not enough to compensate for the increase in PAHs due to T and CTS. The $\Sigma$ PAH16 corresponding to the pyrolysis tars from BT (176.9 mg/g) and BCTS $(153.6 \mathrm{mg} / \mathrm{g})$ are much higher than for coal $(19.1 \mathrm{mg} / \mathrm{g})$. Blends with paraffin or molasses led to a diminution in $\mathrm{PAH}$ content compared to that of the coal. A comparison of the values obtained for the blends BM (15 wt.\% SP4T) and B10M (20 wt.\% SP4T) confirms that inclusion of the torrified sawdust produces a decrease in PAHs. Out of the list of 19 PAHs, 7 appear marked with a (a) and are considered as carcinogenic [24]. If molasses is included in the blends in the same percentage as in the other binders, the $\Sigma \mathrm{PAH} 7$ increases in comparison to that of the coal (BM, $\Sigma \mathrm{PAH} 7=6.1$ $\mathrm{mg} / \mathrm{g}$; Coal, $\Sigma \mathrm{PAH} 7=4.1 \mathrm{mg} / \mathrm{g}$ ) although the total amount of $\mathrm{PAH}$ is lower. When 10 wt.\% of molasses is included in the blend (B10M, which contains $20 \mathrm{wt} . \%$ SP $4 \mathrm{~T}$ and 10 wt.\% molasses) the low contribution of the sawdust to the formation of PAHs counteracts that of the molasses and the total effect is a reduction of the $\Sigma \mathrm{PAH} 7$ from $6.1 \mathrm{mg} / \mathrm{g}$ to 1.7 $\mathrm{mg} / \mathrm{g}$. If paraffin is added to the blend the amount of carcinogenic compounds in the pyrolysis tar is also smaller than in the coal. Again, the use of T and CTS produces tars with a larger amount of carcinogenic compounds. In summary, the following order of contribution by the binders to the content of PAHs in the pyrolysis tars from the blends is proposed: 


\section{IPAH19: $\mathrm{P}<\mathrm{M}<\mathrm{CTS}<\mathrm{T}$ \\ ¿PAH16: $\mathrm{M} \leq \mathrm{P}<\mathrm{CTS}<\mathrm{T}$ \\ ¿PAH7: $\mathrm{P}<\mathrm{M}<\mathrm{T}<\mathrm{CTS}$}

Benzo[a]pyrene $(\mathrm{BaP})$ is considered to be indicative of amount of carcinogenic PAHs present in a product [24]. In this study it has been found that the composition of the pyrolysis oil might be indicative of the amount of carcinogenic PAHs due to the exponential relationship between the concentration of $\mathrm{BaP}$ and the $\mathrm{H} / \mathrm{C}$ atomic ratio as follows:

$$
\mathrm{BaP}=67.348 \mathrm{e}-3.805^{\star} \mathrm{H} / \mathrm{C} \quad \mathrm{r}=0.942
$$

The results obtained from the quantitative analysis of the PAHs is consistent with the results from the FTIR, as can be seen in Figures $4 a$ and $4 b$ where the exponential relationship between the amount of $\mathrm{PAH} 19$ and the aromaticity index and the linear relationship between the amount of $\mathrm{PAH} 7$ and the condensation index are displayed respectively.

\subsection{Main characteristics of the pyrolysis gases}

The compositions of the gases produced from the pyrolysis of the blends, the coal and the torrified sawdust have been included in Figure 5. The hydrocarbons $\left(\mathrm{CH}_{4}\right.$, $\mathrm{C}_{2} \mathrm{H}_{4} / \mathrm{C}_{2} \mathrm{H}_{2}, \mathrm{C}_{2} \mathrm{H}_{6}, \mathrm{C}_{3} \mathrm{H}_{6}$ and $\left.\mathrm{C}_{3} \mathrm{H}_{4}\right)$ are mainly produced in the temperature range of $400-700{ }^{\circ} \mathrm{C}$ with maxima around $500-550{ }^{\circ} \mathrm{C}$. The $\mathrm{H}_{2}$ attains its maximum at around 700 ${ }^{\circ} \mathrm{C}$ and $\mathrm{CO}$ and $\mathrm{CO}_{2}$ are mainly produced between 300 and $600{ }^{\circ} \mathrm{C}$. The coal and the SP4T behave differently. The coal produces high percentages of $\mathrm{CH}_{4}$ and $\mathrm{H}_{2}$, whereas the torrified sawdust produces low percentages of hydrocarbons. The $\mathrm{CO}$ and $\mathrm{CO}_{2}$ concentrations in the gas are the highest. As reported in the literature, the most abundant gases produced during coal carbonization are $\mathrm{CH}_{4}$ and $\mathrm{H}_{2}$ [25], while SP4T emits mostly oxygenated gases and $\mathrm{H}_{2}$ [26]. These results are a consequence of the different chemical compositions of coal and biomass. The $\mathrm{CH}_{4}$ and $\mathrm{H}_{2}$ in biomass are derived from the cracking of the methoxy and $\mathrm{C}-\mathrm{H}$ groups in lignin [27], whereas the carbonyl and carboxyl 
groups in cellulose and hemicellulose are responsible for the production of $\mathrm{CO}$ and $\mathrm{CO}_{2}$ respectively [27]. Coal is mainly constituted by carbon in aromatic systems joined by methylene (- $\left.\mathrm{CH}_{2-}\right)$ and ether (-O-) type bonds and during pyrolysis the decomposition of these structures leads to the formation of aliphatic compounds ranging from $\mathrm{C} 1$ to $\mathrm{C} 3$ and $\mathrm{H}_{2}$. The decomposition of oxygenated functionalities in coal produces the formation of $\mathrm{H}_{2} \mathrm{O}, \mathrm{CO}_{2}$ and $\mathrm{CO}[28]$.

In the case of the blends the most remarkable differences were observed in the evolution of $\mathrm{CH}_{4}$ and $\mathrm{CO}_{2}$ which are considered to be the two main $\mathrm{GHG}$. The blends that include bituminous binders (i.e. BT and BCTS) make a similar contribution to $\mathrm{CO}_{2}$ which is in agreement with the low O/C atomic ratios of T (0.02 wt.\%) and CTS (0.07 wt.\%). Lower still is the evolution of $\mathrm{CO}_{2}$ in the case of the blend prepared with paraffin which was also expected considering that it is made up of hydrocarbons of the $\mathrm{C}_{n} \mathrm{H}_{2 n+2}$ type. On the other hand the blends that include molasses yield the highest concentration of $\mathrm{CO}_{2}$. However, it should be noted that molasses and sawdust are carbon-neutral materials. In light of this the following order of contribution to the production of $\mathrm{CO}_{2}$ and $\mathrm{CH}_{4}$ in the pyrolysis of the blends is proposed:

$$
\begin{aligned}
& \mathrm{CO}_{2}: \mathrm{P}<\mathrm{CTS} \approx \mathrm{T}<\mathrm{M} \\
& \mathrm{CH}_{4}: \mathrm{CTS}<\mathrm{T}<\mathrm{M} \approx \mathrm{P}
\end{aligned}
$$

Although $\mathrm{H}_{2}$ is a valuable component of the pyrolysis gas $[29,30]$, the results indicate that pyrolysis of the blends results in a decrease in $\mathrm{H}_{2}$ production (Figure 5). The evolution of $\mathrm{CO}$ is similar in all the blends. As for the hydrocarbons with a larger number of carbón atoms (C2-C3) their evolution is similar in all the blends, except in the case of $\mathrm{BP}$, which produced high amounts of ethylene, propylene and methylacetylene. Butane, butene and isobutene quantities were also determined but they were not included in Figure 5 because they were found in amounts smaller than $0.5 \%$. 
The gross calorific values (GCV) were calculated taking into account the composition of the gas collected at each temperature. The variation in the GCV of the coal, briquettes and torrified sawdust is plotted in Figure 6. The maximum values appear in the 500-600 ${ }^{\circ} \mathrm{C}$ range. These coincide with the maxima observed in the curves corresponding to the hydrocarbons (see Figure 5). It can be seen that the blend containing paraffin has the highest GCV values. This is because it has the largest number of hydrocarbons with two or three carbon atoms.

\section{Conclusions}

The pyrolysis liquids obtained from BP, $+\mathrm{BM}$ and $\mathrm{B} 10 \mathrm{M}$ contain smaller percentages of $\mathrm{PAHs}$ than those present in the pyrolysis tar from the coal. The $\Sigma \mathrm{PAH} 7$ is also lower in the case of BP and B10M. On the other hand, the tar from the blends with T and CTS contain more than eight times the amount of $\mathrm{PAH} 16$ than the tar from the coal and more than 4.5 times the amount of PAH7. With respect to the emission of greenhouse gases, the blend with paraffin produces the smallest amount of $\mathrm{CO}_{2}$ but the largest amount of $\mathrm{CH}_{4}$. The blends with molasses produce the largest emissions of $\mathrm{CO}_{2}$ despite the fact that these are carbon neutral materials. Their contribution to $\mathrm{CH}_{4}$ is comparable to that of paraffin. The use of paraffin for the blends produces an increase in the GCV of the gas produced during the pyrolysis.

\section{Ackowledgements}

The research leading to these results has received funding from the European Union's Research Programme of the Research Fund for Coal and Steel (RFCS) research programme under grant agreement No. [RFCR-CT-2014-00006]. 


\section{Bibliography}

[1] P. Roy, G. Dias, Prospects for pyrolysis technologies in the bioenergy sector: A review, Renew. Sustain. Energy Rev. 77 (2017) 59-69. doi:10.1016/j.rser.2017.03.136.

[2] H. Suopajärvi, A. Kemppainen, J. Haapakangas, T. Fabritius, Extensive review of the opportunities to use biomass-based fuels in iron and steelmaking processes, J. Clean. Prod. 148 (2017) 709-734. doi:10.1016/j.jclepro.2017.02.029.

[3] O. US EPA, Understanding Global Warming Potentials, US EPA. (2016). https://www.epa.gov/ghgemissions/understanding-global-warmingpotentials (accessed July 4, 2017).

[4] E. Mousa, C. Wang, J. Riesbeck, M. Larsson, Biomass applications in iron and steel industry: An overview of challenges and opportunities, Renew. Sustain. Energy Rev. 65 (2016) 1247-1266. doi:10.1016/j.rser.2016.07.061.

[5] M.S. Kamal, S.A. Razzak, M.M. Hossain, Catalytic oxidation of volatile organic compounds (VOCs) - A review, Atmos. Environ. 140 (2016) 117134. doi:10.1016/j.atmosenv.2016.05.031.

[6] Q. Deng, S. Huang, X. Zhang, W. Zhang, J. Feng, T. Wang, D. Hu, L. Guan, J. Li, X. Dai, H. Deng, X. Zhang, T. Wu, Plasma microRNA expression and micronuclei frequency in workers exposed to polycyclic aromatic hydrocarbons, Environ. Health Perspect. 122 (2014) 719-725. doi:10.1289/ehp.1307080.

[7] J. Wang, X. Zhang, W. Ling, R. Liu, J. Liu, F. Kang, Y. Gao, Contamination and health risk assessment of PAHs in soils and crops in industrial areas of the Yangtze River Delta region, China, Chemosphere. 168 (2017) 976987. doi:10.1016/j.chemosphere.2016.10.113.

[8] L. Qin, J. Han, Y. Zhan, W. Chen, H. Kim, Reduction of Polycyclic Aromatic Hydrocarbon Emission by Porous Alumina Bed Material during Sewage Sludge Incineration, Energy Fuels. 30 (2016) 544-550. doi:10.1021/acs.energyfuels.5b01942.

[9] R. Wei, L. Zhang, D. Cang, J. Li, X. Li, C.C. Xu, Current status and potential of biomass utilization in ferrous metallurgical industry, Renew. Sustain. Energy Rev. 68, Part 1 (2017) 511-524. doi:10.1016/j.rser.2016.10.013.

[10] M.G. Montiano, E. Díaz-Faes, C. Barriocanal, R. Alvarez, Influence of biomass on metallurgical coke quality, Fuel. 116 (2014) 175-182. doi:10.1016/j.fuel.2013.07.070.

[11] M.G. Montiano, A.M. Fernández, E. Díaz-Faes, C. Barriocanal, Tar from biomass/coal-containing briquettes. Evaluation of PAHs, Fuel. 154 (2015) 261-267. doi:10.1016/j.fuel.2015.03.067.

[12] B. Acevedo, C. Barriocanal, R. Alvarez, Pyrolysis of blends of coal and tyre wastes in a fixed bed reactor and a rotary oven, Fuel. 113 (2013) 817-825. doi:10.1016/j.fuel.2012.12.077.

[13] Y. Mochizuki, R. Naganuma, K. Uebo, N. Tsubouchi, Some factors influencing the fluidity of coal blends: Particle size, blend ratio and inherent oxygen species, Fuel Process. Technol. 159 (2017) 67-75. doi:10.1016/j.fuproc.2017.01.017. 
[14] T. Siemieniewska, K. Tomków, A. Jankowska, M. Jasieńko, Influence of the oxygen content of low-rank coals on the development of porosity during carbonization, Fuel. 64 (1985) 481-485. doi:10.1016/0016-2361(85)90081$\mathrm{X}$.

[15] L. Qin, J. Han, W. Ye, S. Zhang, Q. Yan, F. Yu, Characteristics of Coal and Pine Sawdust Co-carbonization, Energy Fuels. 28 (2014) 848-857. doi:10.1021/ef401942a.

[16] B. Acevedo, C. Barriocanal, Fuel-oils from co-pyrolysis of scrap tyres with coal and a bituminous waste. Influence of oven configuration, Fuel. 125 (2014) 155-163. doi:10.1016/j.fuel.2014.01.099.

[17] S.A. Channiwala, P.P. Parikh, A unified correlation for estimating HHV of solid, liquid and gaseous fuels, Fuel. 81 (2002) 1051-1063. doi:10.1016/S0016-2361(01)00131-4.

[18] A. Krzton, D. Cagniant, R. Gruber, J. Pajak, F. Fortin, J.-N. Rouzaud, Application of Fourier self-deconvolution to the FT-i.r. characterization of coals and their N-methyl 2-pyrrolidinone extraction products, Fuel. 74 (1995) 217-225. doi:10.1016/0016-2361(95)92657-R.

[19] P.C. Painter, M. Starsinic, E. Squires, A.A. Davis, Concerning the 1600 $\mathrm{cm}-1$ region in the i.r. spectrum of coal, Fuel. 62 (1983) 742-744. doi:10.1016/0016-2361(83)90317-4.

[20] A.M. Fernández, C. Barriocanal, M.A. Díez, R. Alvarez, Influence of additives of various origins on thermoplastic properties of coal, Fuel. 88 (2009) 2365-2372. doi:10.1016/j.fuel.2008.11.029.

[21] Y. Chen, M. Mastalerz, A. Schimmelmann, Characterization of chemical functional groups in macerals across different coal ranks via micro-FTIR spectroscopy, Int. J. Coal Geol. 104 (2012) 22-33. doi:10.1016/j.coal.2012.09.001.

[22] J.V. Ibarra, E. Muñoz, R. Moliner, FTIR study of the evolution of coal structure during the coalification process, Org. Geochem. 24 (1996) 725735. doi:10.1016/0146-6380(96)00063-0.

[23] R. Tudor, M. Ashley, Enhancement of industrial hydroformylation processes by the adoption of rhodium-based catalyst: Part i development of the LP OXOSM process to the commercial stage, Platin. Met. Rev. 51 (2007) 116-126. doi:10.1595/147106707X216855.

[24] L. Zhao, H. Hou, Y. Shangguan, B. Cheng, Y. Xu, R. Zhao, Y. Zhang, X. Hua, X. Huo, X. Zhao, Occurrence, sources, and potential human health risks of polycyclic aromatic hydrocarbons in agricultural soils of the coal production area surrounding Xinzhou, China, Ecotoxicol. Environ. Saf. 108 (2014) 120-128. doi:10.1016/j.ecoenv.2014.05.034.

[25] R. Alvarez, C. Barriocanal, C.S. Canga, J.S. Canga, M.A. Diez, O.M. Gayol, E.A. Miyar, Coke oven gas control by one-line gas chromatography, Chromatographia. 27 (1989) 611-616. doi:10.1007/BF02258988.

[26] J. Solar, I. de Marco, B.M. Caballero, A. Lopez-Urionabarrenechea, N. Rodriguez, I. Agirre, A. Adrados, Influence of temperature and residence time in the pyrolysis of woody biomass waste in a continuous screw reactor, Biomass Bioenergy. 95 (2016) 416-423. doi:10.1016/j.biombioe.2016.07.004.

[27] H. Yang, R. Yan, H. Chen, D.H. Lee, C. Zheng, Characteristics of hemicellulose, cellulose and lignin pyrolysis, Fuel. 86 (2007) 1781-1788. doi:10.1016/j.fuel.2006.12.013. 
[28] R. Loison, P. Foch, A. Boyer, 1 - Coal in general, in: Coke, ButterworthHeinemann, 1989: pp. 1-58. doi:10.1016/B978-0-408-02870-7.50006-7.

[29] J.M. Bermúdez, A. Arenillas, R. Luque, J.A. Menéndez, An overview of novel technologies to valorise coke oven gas surplus, Fuel Process Technol. 110 (2013) 150.

[30] H.-J. Schröter, Carbon molecular sieves for gas separation processes, Gas Sep. Purif. 7 (1993) 247-251. doi:10.1016/0950-4214(93)80025-R. 
Table 1. Composition of the blends expressed in wt.\%.

\begin{tabular}{lcccccc}
\hline Briquette & Coal & SP4T & Molasses & Paraffin & Tar & CTS \\
\hline BT & 70 & 15 & - & - & 15 & - \\
BCTS & 70 & 15 & - & - & - & 15 \\
BP & 70 & 15 & - & 15 & - & - \\
BM & 70 & 15 & 15 & - & - & - \\
B10M & 70 & 20 & 10 & - & - & - \\
\hline
\end{tabular}


Table 2. Proximate and ultimate analysis of the raw materials.

\begin{tabular}{lcccccc}
\hline Raw materials & Coal & SP4T & Molasses & Paraffin & Tar & CTS \\
\hline Ash (wt.\% db) & 7.3 & 0.3 & 2.8 & 0.2 & 0.2 & 1.7 \\
VM (wt.\% db) & 31.5 & 79.4 & 94.4 & 99.6 & 65.5 & 71.1 \\
C (wt.\% db) & 81.2 & 55.7 & 26.5 & 85.1 & 90.3 & 85.9 \\
H (wt.\% db) & 5.0 & 5.7 & 8.1 & 14.5 & 4.7 & 4.9 \\
N (wt.\% db) & 1.6 & 0.1 & 1.7 & 0.2 & 0.8 & 1.4 \\
S (wt.\% db) & 1.03 & $<0.05$ & 0.18 & $<0.05$ & $<0.05$ & 0.54 \\
O (wt.\% db) & 4.8 & 39.0 & 55.9 & 0.3 & 3.0 & 6.6 \\
H/C & 0.74 & 1.24 & 3.65 & 2.04 & 0.62 & 0.69 \\
O/C & 0.04 & 0.53 & 1.58 & 0.00 & 0.02 & 0.06 \\
\hline
\end{tabular}


Table 3. Ultimate analyses and calorific value of the tars obtained from pyrolized coal, blends and torrified sawdust at $1000^{\circ} \mathrm{C}$.

\begin{tabular}{lccccccc}
\hline Tars 1000 & Coal & BT & BCTS & BP & BM & B10M & SP4T \\
\hline $\mathrm{C}($ wt.\% db) & 85.3 & 83.3 & 85.4 & 80.2 & 75.7 & 71.1 & 20.4 \\
$\mathrm{H}($ wt.\% db) & 8.2 & 7.0 & 7.1 & 10.8 & 8.0 & 8.5 & 9.6 \\
$\mathrm{~N}($ wt.\% db) & 1.5 & 1.4 & 1.7 & 1.0 & 2.4 & 2.7 & 0.2 \\
$\mathrm{~S}($ wt.\% db) & 0.8 & 0.7 & 0.6 & 0.3 & 0.7 & 0.8 & 0.04 \\
$\mathrm{O}($ wt.\% db) & 4.9 & 5.9 & 5.7 & 7.6 & 13.5 & 11.4 & 69.9 \\
$\mathrm{H} / \mathrm{C}^{\mathrm{a}}$ & 1.15 & 1.00 & 1.00 & 1.62 & 1.27 & 1.44 & 5.64 \\
$\mathrm{O} / \mathrm{C}^{\mathrm{a}}$ & 0.04 & 0.05 & 0.05 & 0.07 & 0.13 & 0.12 & 2.57 \\
$\mathrm{Q}(\mathrm{Kcal} / \mathrm{kg})$ & 9526 & 8890 & 9116 & 9883 & 8311 & 8204 & 1934 \\
\hline
\end{tabular}

$\mathrm{Q}$ : Calorific value calculated with the Dulong equation.

a: atomic ratio. 
Table 4. Description of the FTIR indices.

\begin{tabular}{|c|c|c|}
\hline Index & Description & Band region $\left(\mathrm{cm}^{-1}\right)$ \\
\hline Aromaticity (lar) & $\begin{array}{c}v \mathrm{C}-\mathrm{H} \text { aromatic / } \\
v \mathrm{C}-\mathrm{H} \text { aliphatic }+v \mathrm{C}-\mathrm{H} \text { aromatic }\end{array}$ & $\begin{array}{l}\mathrm{A}(3136-2997) / \\
\mathrm{A}(3136-2765)\end{array}$ \\
\hline $\mathrm{C}=\mathrm{O}$ groups $(\mathrm{l} \mathrm{O})$ & $\mathrm{C}=\mathrm{O} / v \mathrm{C}=\mathrm{C}$ & $\mathrm{A}(1770-1650) / \mathrm{A} 1600$ \\
\hline Condensation index (IC) & $\begin{array}{c}\text { Out of plane aromatic } \sigma \mathrm{C}-\mathrm{Har} \\
\text { vibration } / \mathrm{vC}=\mathrm{C}\end{array}$ & $\mathrm{A}(700-900) / \mathrm{A} 1600$ \\
\hline $\begin{array}{l}\text { Four neighbouring } \\
(\mathrm{H} 750)\end{array}$ & $\begin{array}{c}\sigma \mathrm{CHar} / \sigma \text { aromatic } \mathrm{C}-\mathrm{H} \text { out of } \\
\text { plane }\end{array}$ & $\mathrm{A} 750 / \mathrm{A}(700-900)$ \\
\hline Chain length $\mathrm{I}_{\mathrm{CH} 3 / \mathrm{CH} 2}$ & $\sigma \mathrm{CH} 3-\mathrm{Ar} / \sigma \mathrm{CH} 2-\mathrm{Ar}$ & $\mathrm{H} 1375 / \mathrm{H} 1450$ \\
\hline
\end{tabular}

$v$ : stretching vibration; $\sigma$ : bending vibration 
Table 5. Indices calculated from the areas and heights of the FTIR spectra bands of the pyrolysis tars/oils.

\begin{tabular}{lccccc}
\hline & Iar & $\mathrm{IC}$ & $\mathrm{H} 750$ & $\mathrm{I}_{\mathrm{CH} 3 / \mathrm{CH} 2}$ & lo \\
\hline Coal & $0.109 \pm 0.001$ & $1.153 \pm 0,031$ & $0.286 \pm 0.001$ & $0.490 \pm 0.005$ & $0.408 \pm 0.003$ \\
BT & $0.248 \pm 0.011$ & $1.996 \pm 0.103$ & $0.382 \pm 0.003$ & $0.474 \pm 0.024$ & $0.956 \pm 0.019$ \\
BCTS & $0.237 \pm 0,001$ & $2.329 \pm 0.035$ & $0.411 \pm 0.002$ & $0.457 \pm 0.005$ & $0.656 \pm 0.012$ \\
BP & $0.041 \pm 0.000$ & $0.884 \pm 0.003$ & $0.237 \pm 0.004$ & $0.249 \pm 0.003$ & $1.555 \pm 0.020$ \\
BM & $0.092 \pm 0.006$ & $0.696 \pm 0.131$ & $0.318 \pm 0.001$ & $0.452 \pm 0.032$ & $0.904 \pm 0.030$ \\
B10M & $0.110 \pm 0.016$ & $0.563 \pm 0.140$ & $0.316 \pm 0.007$ & $0.437 \pm 0.021$ & $0.969 \pm 0.116$ \\
SP4T & $0.056 \pm 0.031$ & $0.456 \pm 0.089$ & $0.279 \pm 0.020$ & $0.877 \pm 0.016$ & $3.231 \pm 0.270$ \\
\hline
\end{tabular}


Table 6. Quantification of the PAHs present in the pyrolysis tars/oils expressed in $\mathrm{mg} / \mathrm{g}$.

\begin{tabular}{|c|c|c|c|c|c|c|c|c|}
\hline $\mathrm{PAH}$ & Structure & Coal & BT & BCTS & $\mathrm{BP}$ & BM & B10M & SP4T \\
\hline Naphthalene* & & 2.99 & 44.58 & 28.61 & 3.17 & 1.54 & 2.58 & 1.51 \\
\hline Acenaphthylene* $^{*}$ & & 2.09 & 10.33 & 10.45 & 1.35 & 1.03 & 1.30 & 0.58 \\
\hline Acenaphthene $^{*}$ & & 2.15 & 6.37 & 4.77 & 0.65 & 1.02 & 1.17 & 0.31 \\
\hline Fluorene* $^{*}$ & & 2.74 & 8.95 & 10.19 & 1.18 & 1.44 & 1.73 & 0.30 \\
\hline Phenanthrene* $^{*}$ & & 2.45 & 32.67 & 30.06 & 3.25 & 2.07 & 1.92 & 0.58 \\
\hline Anthracene* & & 1.38 & 7.64 & 8.97 & 1.88 & 1.24 & 0.88 & 0.28 \\
\hline Fluoranthene* & & 0.60 & 23.54 & 19.60 & 1.15 & 0.56 & 0.48 & 1.05 \\
\hline Pyrene* & & 0.92 & 19.65 & 14.78 & 1.22 & 0.86 & 0.82 & 1.00 \\
\hline Benzo(a)fluorene & & 0.90 & 2.58 & 4.29 & 0.40 & 1.30 & 0.55 & 0.61 \\
\hline Benzo(b)fluorene & & 1.18 & 2.46 & 3.88 & 0.45 & 0.79 & 0.75 & 0.30 \\
\hline Benzo(a)anthracene ${ }^{\star a}$ & & 1.22 & 7.61 & 8.76 & 1.02 & 1.13 & 0.65 & 0.47 \\
\hline Chrysene ${ }^{\star a}$ & & 0.89 & 8.32 & 9.56 & 0.00 & 2.60 & 0.00 & 1.23 \\
\hline Benzo(b)fluoranthene* a & & 0.47 & 0.26 & 2.88 & 0.03 & 0.91 & 0.25 & 0.00 \\
\hline Benzo(k)fluoranthene*a & & 0.40 & 2.48 & 1.44 & 0.00 & 0.33 & 0.13 & 0.00 \\
\hline
\end{tabular}


Table 6 cont. Quantification of PAHs present in pyrolysis tars/oils expressed in mg/g.

PAH
Benzo(e)pyrene
Benzo(a)pyrene* a




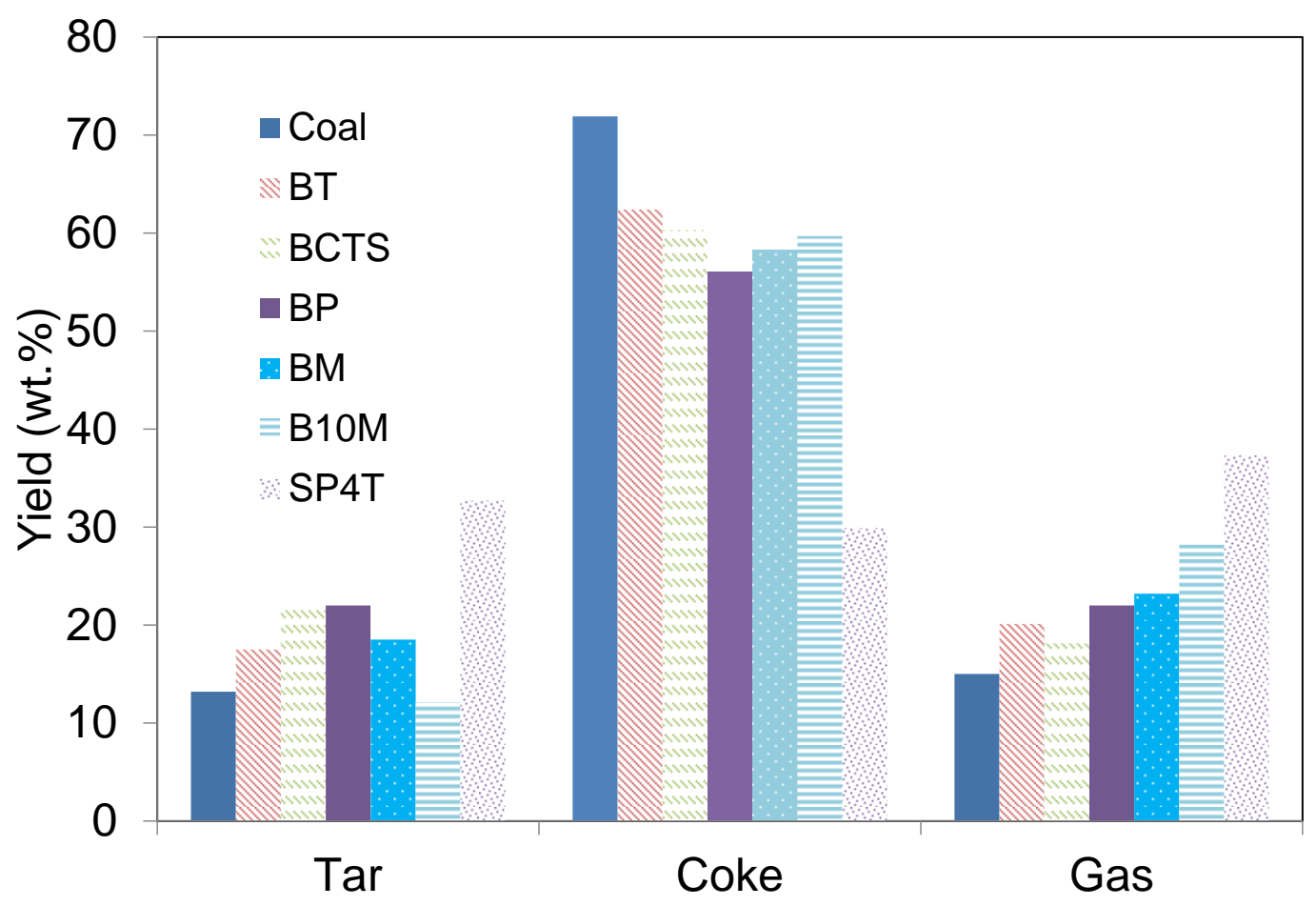

Figure 1. Mass balance corresponding to the pyrolysis of the blends, the coal and the torrified sawdust. 


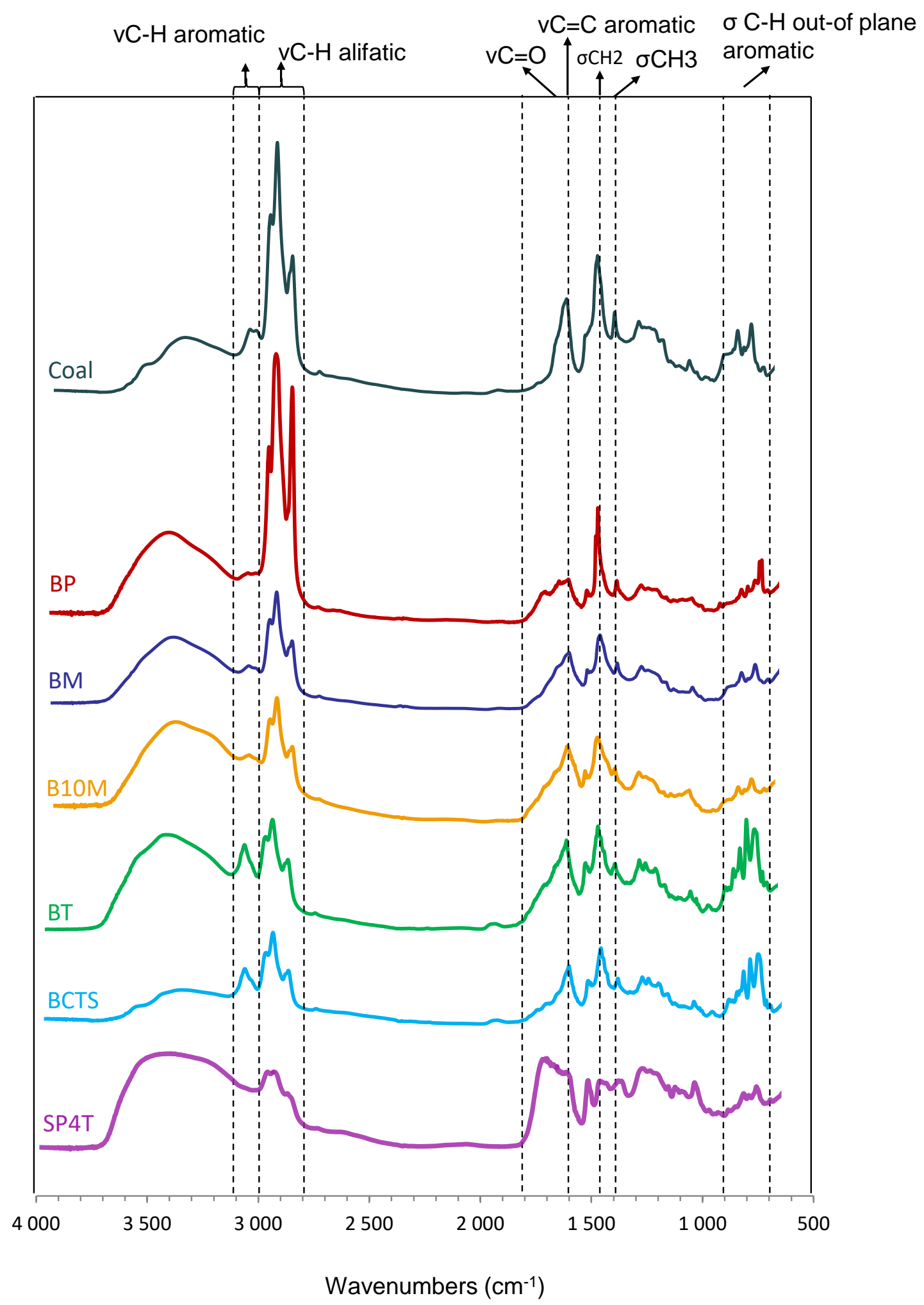

Figure 2. FTIR spectra of the pyrolysis tars obtained at $1000^{\circ} \mathrm{C}$. 

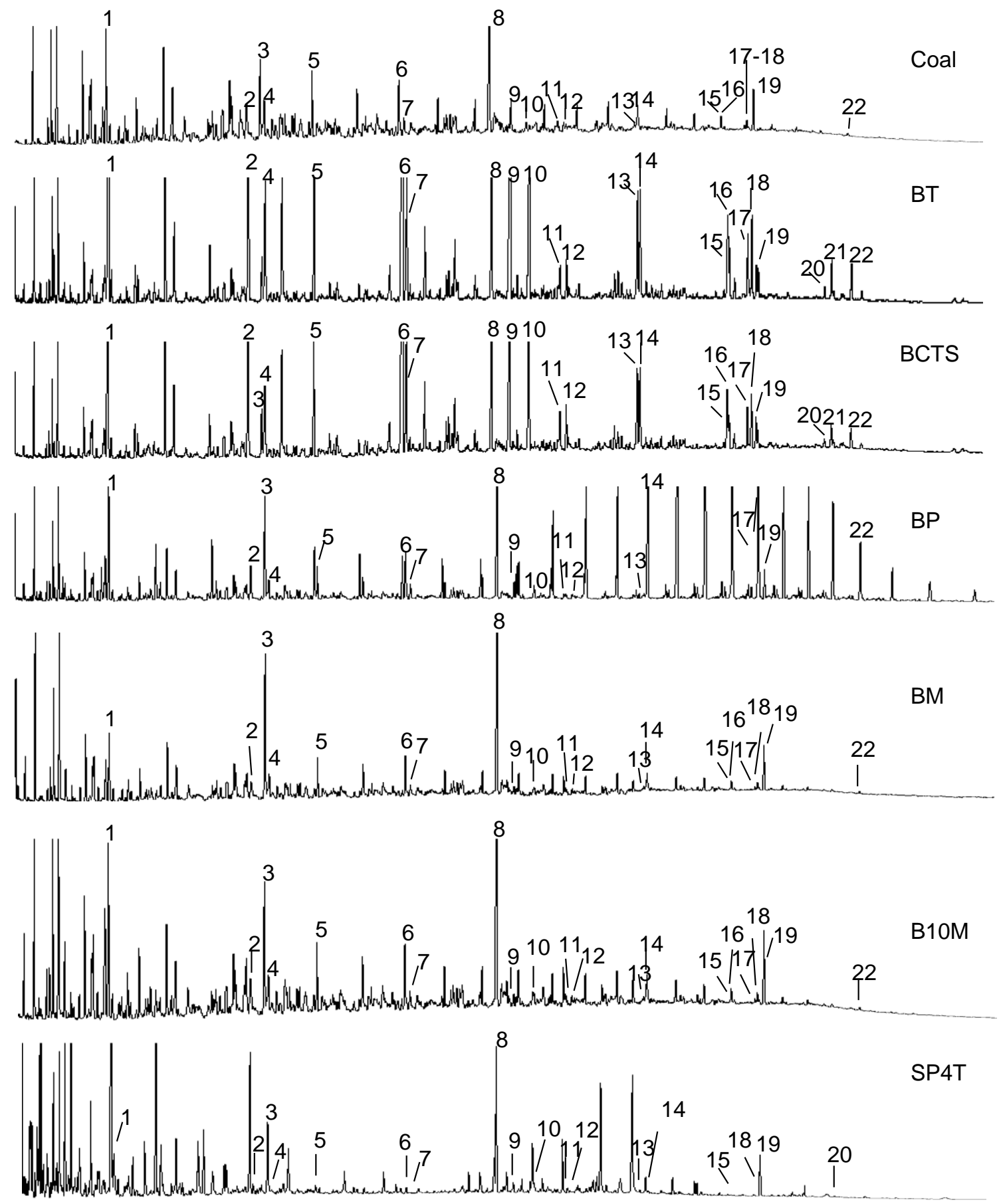

Time (min)

Figure 3. Capillary gas chromatograms of the volatile fractions of the toluene soluble fractions of pyrolysis tars. Peak identification: 1. Naphthalene, 2. Acenaphthylene, 3. D10-Acenaphthene, 4. Acenaphthene, 5. Fluorene, 6. Phenanthrene, 7. Anthracene, 8. 2-Ethylanthracene, 9. Fluoranthene, 10. Pyrene, 11. Benzo(a)fluorene, 12.

Benzo(b)fluorene, 13. Benzo(a)anthracene, 14. Crysene, 15. Benzo(b)fluoranthene, 16. Benzo(k)fluoranthene, 17. Benzo(e)pyrene, 18. Benzo(a)pyreno, 19. D12-Perylene, 20. Indene(1,2,3-c,d)pyrene, 21. Dibenzo(a,h)anthracene, 22. Benzo(g,h,i)perylene. 

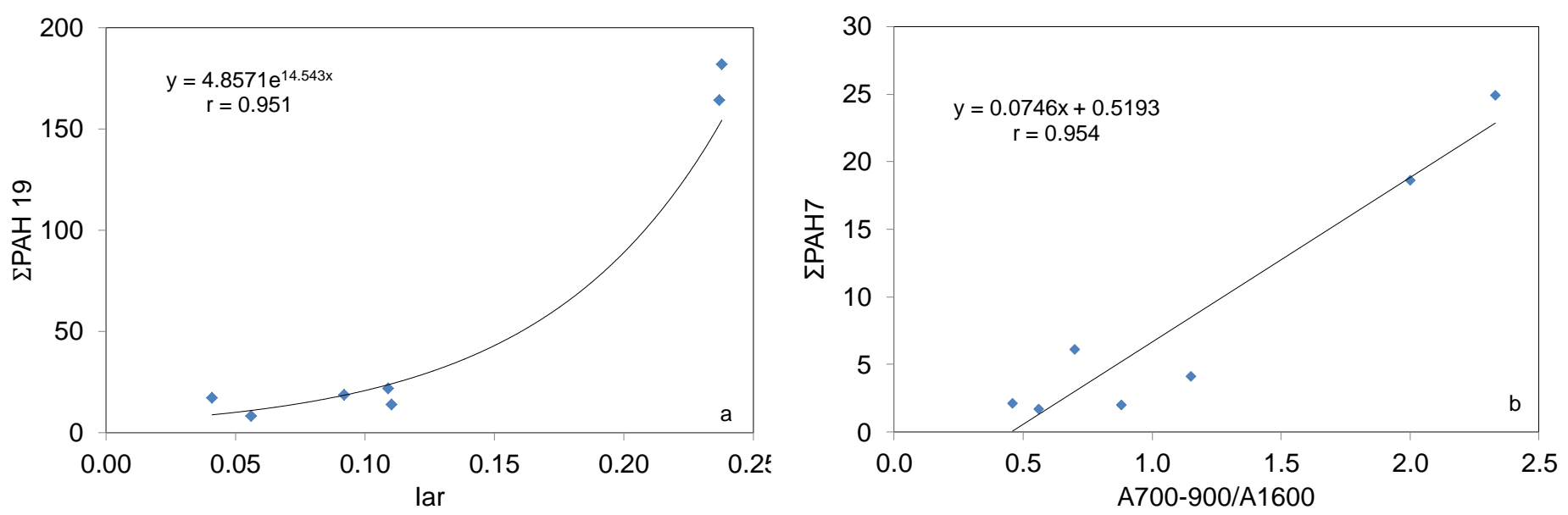

Figure 4. Relationship between the indices derived from FTIR and the amount of PAH in the pyrolysis tars. 

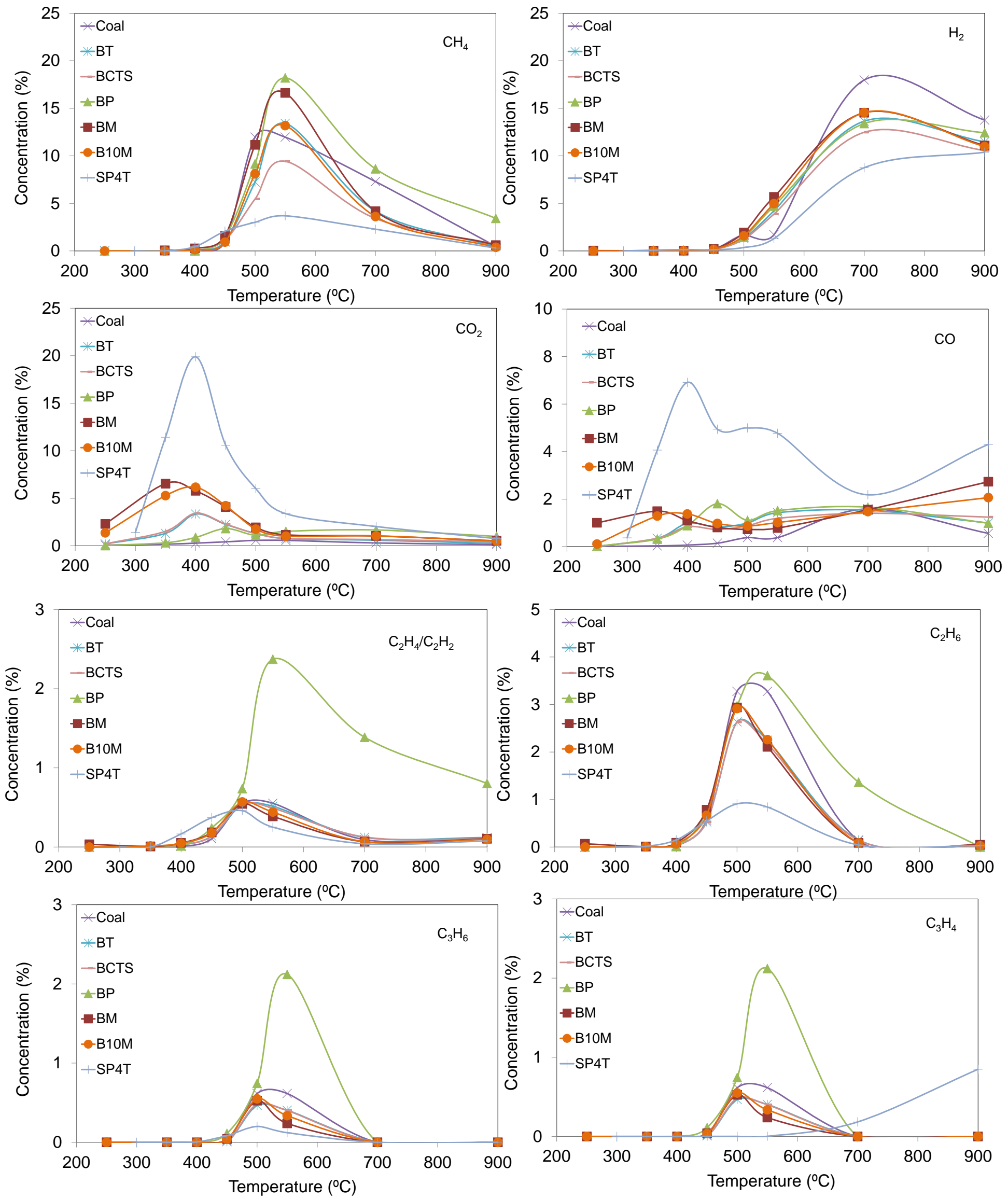

Figure 5. Evolution of the gases during pyrolysis. 


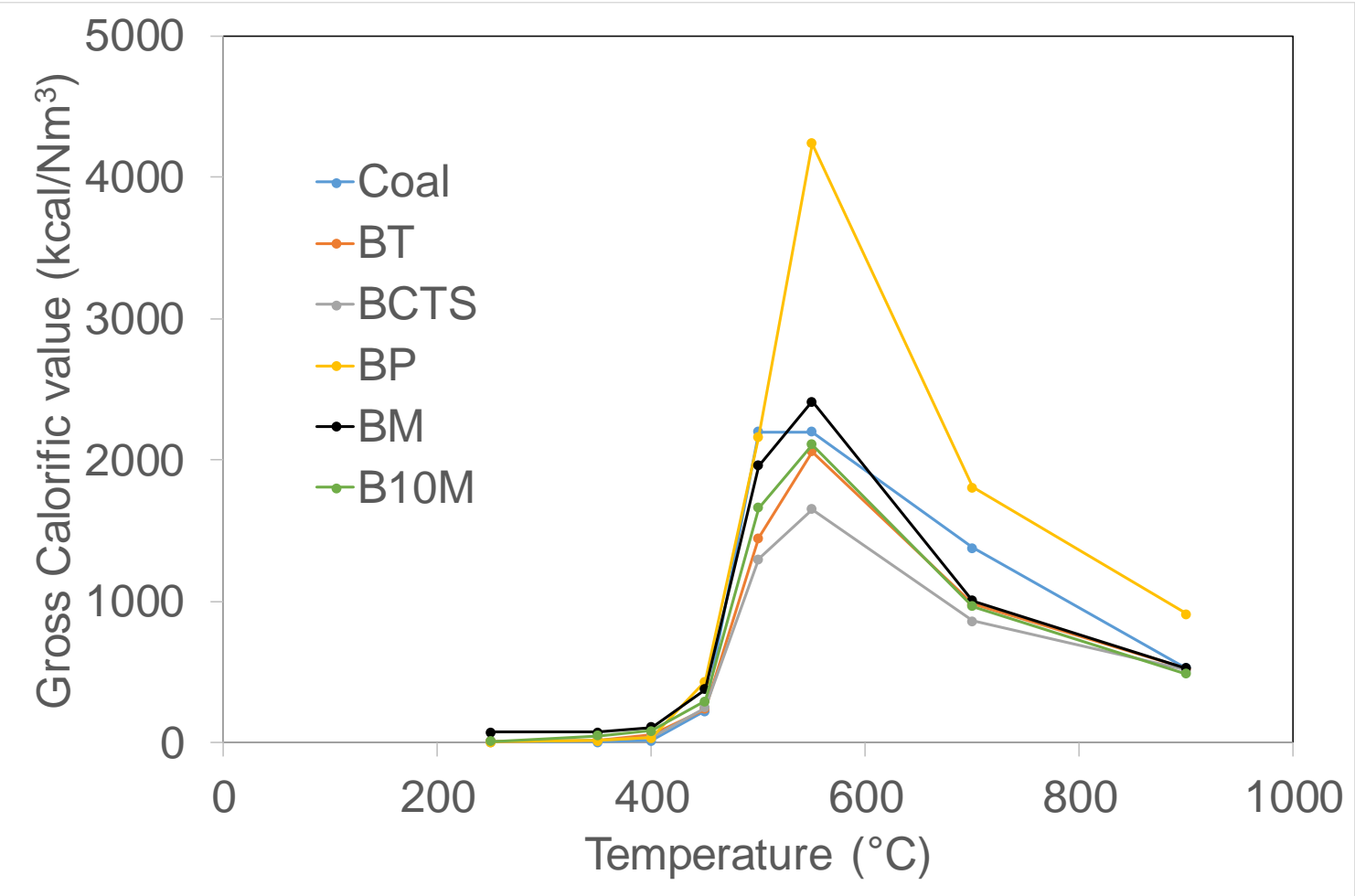

Figure 6. Variation of gross calorific value with temperature. 
